\title{
O ANTAGONISMO DA RESOLUÇÃO CNE/CP 02/2019: REFLEXÕES SOBRE A ATUALIZAÇÃO CURRICULAR DO CURSO DE PEDAGOGIA DA FACED/UFBA COM BASE NA RESOLUÇÃO CNE/CP 02/2015
}

The antagonism of resolution CNE/CP 02/2019: reflections on the curricular update of the pedagogy course at FACED/UFBA based on resolution CNE/CP 02/2015

El antagonismo de la resolución CNE/CP 02/2019: reflexiones sobre la actualización curricular del curso de pedagogía en FACED/UFBA con base en la resolución CNE/CP 02/2015

Ronaldo Figueiredo Venas*

Rejane de Oliveira Alves**

Leila da Franca Soares***

https://doi.org/10.38117/2675-181X.formov2021.v3i1n5.211-230.

\section{Resumo}

O objetivo deste artigo é refletir sobre o processo de atualização curricular da formação em Pedagogia da Faculdade de Educação da Universidade Federal da Bahia (FACED/UFBA) fundamentado pela Resolução CNE/CP 02/2015. A pergunta norteadora consistiu em: quais são as implicações da Resolução CNE/CP 02/2019 para a formação de professores/as no curso de Pedagogia? Nesse sentido, problematizou-se a vertente antagônica desta Resolução em relação à anterior, uma vez que as discussões em torno do currículo foram mediadas pela legislação aprovada em 2015. O diálogo proposto neste estudo se fez com os teóricos: Saviani (2010), Aguiar (et al 2006; 2019), Libâneo e Pimenta (1999) e Curado Silva (2020), entre outros. A metodologia que embasou a investigação foi a descritivo-analítica. Por fim, o resultado deste trabalho culminou com a atualização curricular do Projeto Pedagógico do Curso de Pedagogia com a defesa intransigente da formação inicial na modalidade presencial.

Palavras-chave: Formação de Professores/as; Diretrizes Curriculares Nacionais; Projeto Pedagógico; Licenciatura em Pedagogia; Resolução CNE 02/2019. 


\begin{abstract}
The purpose of this article is to reflect on the curriculum update process of the Pedagogy course at FACED/UFBA based on Resolution CNE/CP 02/2015. The guiding question was: what are the implications of Resolution CNE/CP 02/2019 for teacher training in the Pedagogy course? In this sense, we problematize the antagonistic aspect of this resolution in relation to the previous one, since the discussions around the curriculum were mediated by the Resolution approved in 2015. The dialogue proposed in this work was made with the theorists: Saviani (2010), Aguiar (et al 2006; 2019), Libâneo and Pimenta (1999) and Curado Silva (2020), among others. The methodology that supported the investigation was descriptive-analytical. Finally, the result of this work culminated in the curricular updating of the Pedagogical Project of the Pedagogy course with the uncompromising defense of initial training in the face-to-face modality.
\end{abstract}

Keywords: Teacher Education; National Curriculum Guidelines; Pedagogical project; Degree in Pedagogy; CNE Resolution 02/2019.

\title{
Resumen
}

El propósito de este artículo es reflexionar sobre el proceso de actualización curricular del curso de Pedagogía de la FACED/UFBA en base a la Resolución CNE/CP 02/2015. La pregunta orientadora fue: ¿Cuáles son las implicaciones de la Resolución CNE/CP 02/2019 para la formación de docentes en el curso de Pedagogía? En este sentido, problematizamos el aspecto antagónico de esta resolución con relación a la anterior, ya que las discusiones en torno al currículo estuvieron mediadas por la Resolución aprobada en 2015. El diálogo propuesto en este trabajo se realizó con los teóricos: Saviani (2010), Aguiar (et al 2006; 2019), Libâneo y Pimenta (1999) y Curado Silva (2020), entre otros. La metodología que sustenta la investigación fue descriptiva-analítica. Finalmente, el resultado de este trabajo culminó en la actualización curricular del Proyecto Pedagógico del Curso de Pedagogía con la defensa sin concesiones de la formación inicial en la modalidad presencial.

Palabras clave: Formación de profesores; Directrices del plan de estudios nacional; Proyecto pedagógico; Licenciada en Pedagogía; Resolución CNE 02/2019.

\section{Introdução}

No campo da formação de professores/as, nós, pesquisadores, estudamos sobre diferentes projetos educacionais em disputa na sociedade que têm gerado leis e resoluções que implicaram na criação e reformulação do curso de Pedagogia no Brasil. Percebendo o seu caráter político e o seu papel social, entendemos como relevante e urgente o estudo 
O antagonismo da Resolução CNE/CP 02/2019: Reflexões sobre a atualização curricular do curso de Pedagogia da FACED/UFBA com base na Resolução CNE/CP 02/2015

e reflexão crítica a respeito da Resolução 02/2019, que tem produzido preocupações sobre os desdobramentos para a formação. Neste cenário, destacamos a importância das associações de classe como a Associação Nacional pela Formação dos Profissionais da Educação (ANFOPE) na luta e enfrentamento por uma formação crítica e reflexiva. Corroborando com a ANFOPE, seguimos na luta e resistência por um Projeto de Educação democrático e inclusivo, que tem sua pauta refletida na Resolução 02/2015, a qual acreditamos e defendemos como proposta possível para uma formação de qualidade.

É nesse contexto que este trabalho apresenta, na primeira parte, a trajetória do curso de Pedagogia da Faculdade de Educação da Universidade Federal da Bahia (FACED/UFBA) criado sob os efeitos das legislações, como a Lei 5.692/71, que criou habilitações e impôs um modelo de formação autoritário, sem a participação de docentes. $\mathrm{Na}$ segunda parte, os avanços alcançados com a atualização curricular realizada com a Resolução CNE/CP 02/2015, que teve como prática a discussão do projeto em assembleias e reuniões setoriais; a incorporação dos direitos humanos como prática obrigatória, além de outros avanços. Na terceira parte refletimos sobre os retrocessos que a implantação da Resolução CNE/CP 02/2019 pode trazer um retorno ao passado, em que os profissionais da educação não participam da elaboração e discussão da legislação e têm que se submeter a um modelo prescritivo, fragmentado e acrítico.

\section{Projetos em disputa: Trajetória do curso de Pedagogia da UFBA em face da legislação nacional}

Em 1941, na Faculdade de Filosofia e Ciências Humanas da Universidade da Bahia surgiu o curso de Pedagogia com o bacharelado e a licenciatura, que teve como finalidade formar professores no ensino superior para atuar na educação básica e nos sistemas de ensino. Inicialmente, o curso funcionou no prédio da antiga escola normal no centro da cidade, mas, posteriormente, em 1968, foi sediado no atual prédio da Faculdade de Educação. Nesse momento, o curso de pedagogia teve que cumprir a legislação nacional e passou a ofertar as habilitações, instituídas pela legislação do extinto Conselho Federal de Educação com o propósito de formar profissionais que pudessem atuar no Magistério do Curso Normal, na Supervisão Escolar, na Orientação Educacional e outras áreas de atuação que não foram adotadas pela UFBA.

A partir da lei n. 5.692/71, passamos a ter uma regulamentação da organização das atividades docentes e não docentes dentro da instituição escolar, entre elas: a de supervisor pedagógico - que, tendo um perfil definido em meio ao autoritarismo militar 
e a um tecnicismo que influenciava a área pedagógica - passou a ter um papel importante no desenvolvimento do trabalho docente.

A essa teoria pedagógica correspondeu uma reorganização das escolas
que passaram por um crescente processo de burocratização. Acreditava-
se que o processo se racionalizava à medida que se agisse
planificadamente. Para tanto, era mister baixar instruções minuciosas
sobre como proceder com vistas a que os diferentes agentes cumprissem
cada qual as tarefas específicas acometidas a cada um no amplo
espectro em que se fragmentou o ato pedagógico. (SAVIANI, 2010, p.
383).

Por outro lado, Libâneo e Pimenta (1999), discutindo as ambiguidades que historicamente foram sendo inseridas no curso de Pedagogia, salientam:

O curso de pedagogia - sem entrar agora no mérito de sua função, isto é, de formar professores ou especialistas ou ambos - pouco se alterou em relação à Resolução no 252/69. Experiências alternativas foram tentadas em algumas instituições e o antigo CFE expediu alguns pareceres sobre "currículos experimentais", mas nenhum deles, a rigor, apresenta algo realmente inovador. Possíveis "novidades" no chamado "curso de pedagogia" seriam, por exemplo, a atribuição, ao lado de outras, da formação em nível superior de professores para as séries iniciais do Ensino Fundamental, supressão das habilitações (administração escolar, orientação educacional, supervisão escolar etc.) e alterações na denominação de algumas disciplinas. Alterações geralmente inócuas, pois, na maior parte dos casos, foram mantidos a prática da grade curricular e os mesmos conteúdos das antigas disciplinas, por exemplo, 'Organização do trabalho pedagógico' manteve o conteúdo da anterior 'Administração escolar'. (LIBÂNEO; PIMENTA, 1999, p. 240).

Reestruturado em 1999, o currículo do curso de Pedagogia passou a formar o Coordenador do Trabalho Pedagógico, ou seja, um profissional que sintetiza a antiga formação especializada por habilitação (Administração Escolar, Orientação Educacional, Supervisão Escolar etc.) em outra mais generalista e flexível. As mudanças realmente significativas somente vieram com o advento das Diretrizes Curriculares Nacionais para o curso de Pedagogia (2006).

Aguiar (et al, 2006, p. 824), tratando das diretrizes curriculares do curso de Pedagogia, discute o papel das associações nos debates e conquistas da época. Segundo a autora, as reformulações curriculares feitas pela maioria das universidades públicas e particulares adotaram a docência como base da identidade do curso de Pedagogia e, desse modo, extinguiram as habilitações. 
O antagonismo da Resolução CNE/CP 02/2019: Reflexões sobre a atualização curricular do curso de Pedagogia da FACED/UFBA com base na Resolução CNE/CP 02/2015

Segundo as autoras acima citadas, o movimento de discussão e elaboração das diretrizes da Pedagogia tem um marco importante em 1998, quando a comissão de especialistas, formada para elaborar as diretrizes da Pedagogia, debateu as temáticas em âmbito nacional por meio da Associação Nacional dos Professores pela Formação dos Profissionais da Educação (ANFOPE), Fórum Nacional de Diretores de Faculdades e Centros de Educação (FORUNDIR), Associação Nacional de Política e Administração da Educação (ANPAE), Associação Nacional de Pesquisa e Pós-graduação (ANPED), Centro de Estudos, Educação e Sociedade (CEDES) e Executiva Nacional dos Estudantes de Pedagogia.

\begin{abstract}
Neste intervalo entre maio de 1999 e junho de 2004, as várias iniciativas do MEC com relação à formação de professores e ao próprio curso de pedagogia (Parecer da Câmara do Ensino Superior - CES nº 133/01, Resoluções $n^{\circ} 01$ e 02/2002, que instituem diretrizes para a formação de professores) causaram mais transtornos do que encaminhamentos positivos para tais cursos, a tal ponto que hoje a diversidade de estruturas exigirá provavelmente do Poder Público um acompanhamento rigoroso, bem como processos de avaliação da formação oferecida, de modo que se preservem as iniciativas positivas e se estabeleçam metas para o aprimoramento da qualidade de outras. (AGUIAR et al, 2006, p. 825).
\end{abstract}

Durante todo esse processo foi sendo reafirmado que a Universidade era o locus primordial da formação. A ANFOPE, em documento publicado no ano de 1998, reafirma que a docência é a base de todos os profissionais licenciados e pedagogos, por isso caminhou no sentido de superar "a fragmentação entre as habilitações no curso de pedagogia e a dicotomia entre a formação dos pedagogos e dos demais licenciados" (ANFOPE apud AGUIAR, 2006, p. 826). Desse modo, considera-se a formação para o ensino como a mesma base para todos os profissionais de educação. Mas as discussões permaneceram em torno de um projeto de formação, o que culminou, mais adiante, na aprovação da Resolução 02/2015 que passaremos a discutir na sequência.

\title{
Desdobramentos da Resolução CNE/CP 02/2015 na atualização curricular do curso de Pedagogia da FACED/UFBA
}

Em 1 de julho de 2015, foram aprovadas as Diretrizes Curriculares Nacionais para a formação inicial em nível superior (cursos de licenciatura, cursos de Formação Pedagógica para graduados e cursos de segunda licenciatura) e para a formação continuada. Essa nova normativa não substituiu as Diretrizes Curriculares Nacionais para 
o Curso de Graduação em Pedagogia, licenciatura de 2006. Alguns elementos que já estavam presentes nas Diretrizes de 2006 (Resolução 01/2006) foram reafirmados e ampliados, tais como a atenção para os estágios supervisionados e para a formação que considere as diversidades. Ressalta-se que a Resolução CNE/CP 02/2015 embasou as discussões e reformulação do Projeto Pedagógico dos Cursos de Pedagogia (diurno e noturno) da Faculdade de Educação da Universidade Federal da Bahia (FACED/UFBA).

A referida Resolução propõe a não fragmentação do processo formativo e formacional, reafirmando a importância de uma formação teórico-prática, ao destacar entre uma de suas considerações fundamentais, "a necessidade de articular as Diretrizes Curriculares Nacionais para a Formação Inicial e Continuada, em Nível Superior, e as Diretrizes Curriculares Nacionais para a Educação Básica”. Foi esse documento legal que auxiliou a comunidade acadêmica a olhar para o Curso de Pedagogia da FACED-UFBA para que tivéssemos no horizonte um Projeto de Curso que refletisse os anseios de uma formação acadêmico-científica-pedagógica dos/as futuros/as profissionais licenciados/as em Pedagogia.

\section{A ideia filosófica de formação aqui cultivada vai na direção de um gesto ético-político entretecido ao currículo, concebido como experiência cultural. O formativo é configurado, portanto, por escolhas simbólicas. Esse, faz-se necessário ressaltar, é um conjunto de pautas curriculares e formacionais que a escola pode experimentar como possibilidades de qualificação do seu protagonismo político. (MACEDO, 2018, p. 1315).}

Concordando com o autor citado acima, há de se destacar também que a Resolução 02/2015 traz explicitamente os princípios fundamentais para a formação inicial e continuada de professores/as, a saber: “a) sólida formação teórica e interdisciplinar; b) unidade teoria-prática; c) trabalho coletivo e interdisciplinar; d) compromisso social e valorização do profissional da educação; e) gestão democrática; f) avaliação e regulação dos cursos de formação". Esses princípios fundantes foram ganhando força na produção escrita do Projeto de Curso que almejamos porque mostra não só o compromisso com a qualidade da formação de professores/as que iniciam a carreira, mas também daqueles/as que já atuam.

A Associação Nacional pela Formação dos Profissionais da Educação (ANFOPE) escreveu um documento acerca das Diretrizes Curriculares de Formação Inicial e Continuada do Magistério da Educação Básica, fazendo a análise crítica do Parecer CNE/CP n. 2, de 09/06/2015, e sua Resolução CNE/CP n. 2, de 01/07/2015, que consta nos Anais do XVIII Encontro Nacional da ANFOPE, realizado em Goiânia, no dia 7 de Dezembro de 2016, com o título Políticas de Formação e Valorização dos Profissionais da Educação: Conjuntura Nacional Avanços e Retrocessos. Neste documento, há 
O antagonismo da Resolução CNE/CP 02/2019: Reflexões sobre a atualização curricular do curso de Pedagogia da FACED/UFBA com base na Resolução CNE/CP 02/2015

destaque específico para a organização e ênfase nas Diretrizes Curriculares Nacionais (DCN) que:

- incorporam a formação para a gestão no percurso formativo de todos os estudantes, de todas as licenciaturas, para todas as áreas, níveis e modalidades de ensino;

- apontam possibilidades para um Subsistema Nacional de Formação de Professores para a Educação Básica, quando propõem a articulação entre a formação inicial e a continuada, levando, também, em consideração as condições de formação acadêmica, as condições materiais de trabalho, os planos de carreira e de salários;

- aproximam, também, as instituições formadoras e o campo de atuação profissional, orientando os estudantes no mundo do trabalho, desde o início do curso mediante a Prática com 400 horas e Estágio Supervisionado, também com 400 horas. (ANFOPE, 2016, p. 34-35).

Assim como a ANFOPE reitera, neste documento, que os princípios formativos defendidos na Resolução 02/2015 mostram um avanço para a Política de Formação, também compreendemos que esse documento traduz um pouco dos anseios dos/as profissionais formadores/as, porque uma vez que nos auxilia a organizar e planejar a formação, também nos ajuda a repensar nosso percurso formativo, afinal, quem forma o/a formador/a? A demarcação da carga horária mínima de 3.200 horas de efetivo trabalho acadêmico na formação inicial que se materializa nos cursos, de oito semestres ou quatro anos, também foi importante para a organização das atividades de ensino-pesquisaextensão nas Instituições formadoras.

De acordo ainda com a ANFOPE (2016, p. 35), essa orientação pedagógica representa um compromisso político com a sólida formação profissional "que permita a apropriação do processo de trabalho pedagógico, criando condições de exercer uma análise crítica da sociedade brasileira e da realidade educacional" (cf. Documentos Finais, ANFOPE, 1983, 1986, 1996, 1998, 2002, 2004, 2006, 2008, 2010, 2012, 2014). Mas alerta que as Instituições privadas ainda precisam avançar, uma vez que as condições de trabalho focadas prioritariamente no ensino não favorecem a articulação ensino-pesquisaextensão que forma o tripé das Universidades.

Ao observarmos a construção da Resolução CNE/CP 02/2015 nas Disposições Gerais, em seu Art. $1^{\circ}$ que institui a presente Resolução, as Diretrizes Curriculares Nacionais para a Formação Inicial e Continuada em Nível Superior de Profissionais do Magistério para a Educação Básica, explicita que o documento está organizado em "princípios, fundamentos, dinâmica formativa e procedimentos a serem observados nas políticas, na gestão e nos programas e cursos de formação, bem como no planejamento, nos processos de avaliação e de regulação das instituições de educação que as ofertam". 
Essa demarcação inicial já demonstra que não se trata de um documento com imposições de ordem prática sobre a formação de novos docentes, mas de um documento orientador, que apresenta possibilidades e que respeita a diversidade das complexas realidades de nosso país. Esse entendimento nos permitiu liberdade para dialogar com os nossos paresímpares e com nossos estudantes da Graduação, a fim de "desenhar" um formato dinâmico para as ações formativas que pretendemos refletir no documento formal; documento esse que apresentamos à comunidade acadêmica, após o processo de escuta, de plenárias participativas com professores/as e estudantes da comunidade acadêmica FACED/UFBA.

Com o objetivo de subsidiar a atualização curricular da proposta pedagógica foi necessária uma investigação sobre o perfil socioeconômico dos estudantes. Os dados foram coletados através da aplicação de questionários com perguntas abertas e fechadas, aos alunos, no ano de 2018. Os questionários foram aplicados pelos próprios estudantes do curso de Pedagogia (no formato impresso e também online). Dos 734 estudantes regularmente matriculados, 183 responderam a pesquisa, conforme descrevemos abaixo. Tais informações também foram descritas no Projeto Pedagógico do Curso de Licenciatura em Pedagogia (2019) que foi encaminhado para a Pró-Reitoria de Graduação (PROGRAD/UFBA) - Núcleo de Currículo - para análise e aprovação.

Reiteramos que este estudo foi embasado pela metodologia da pesquisa descritivo-analítica que, segundo Gil (2008), se desenvolve a partir da descrição das características de determinadas populações ou fenômenos. Entretanto, fomos além da descrição, buscando analisar quais necessidades formativas eram latentes naquele contexto educacional. Assim, a partir da observação, estudo e análise das informações, buscamos construir, de forma coletiva e colaborativa, um Projeto Formativo que atendesse aos anseios de nossa Faculdade de Educação.

Neste cenário, a fim de contextualizar quem são os sujeitos que cursam Licenciatura em Pedagogia na FACED-UFBA, apresentamos os resultados da pesquisa realizada. Dos 183 respondentes, 37,2\% são alunos do Noturno e 62,8\% são alunos do Diurno; $82 \%$ se definem como "ela", 16,4\% se definem como "ele", o restante se declarada como "outros"; 50,8\% são negros/as, 34,4\% são pardos/as, 14,8\% são brancos/as e nenhuma identificação para amarelo e/ou indígena. Ou seja, mais de $80 \%$ dos/as estudantes de Pedagogia são negros/as e pardos/as, o que é um dado muito representativo para o estado da Bahia.

Sobre o estado civil dos entrevistados, $71,6 \%$ se denominam solteiro/a, $16,9 \%$ casado/a, 8,7\% união estável/morando juntos. Sobre a realização de atividade 
O antagonismo da Resolução CNE/CP 02/2019: Reflexões sobre a atualização curricular do curso de Pedagogia da FACED/UFBA com base na Resolução CNE/CP 02/2015

remunerada, 47,8\% estão em atividade remunerada na área da docência, 27,5\% estão realizando atividade remunerada, mas em área diferente da docência e $24,7 \%$ não estão realizando atividade remunerada.

Com relação ao motivo pela escolha do curso, $77 \%$ ingressaram por primeira opção e $23 \%$ por opção de ingressar na UFBA, considerando a nota obtida no exame nacional. Uma informação importante é que $89,1 \%$ dos/as entrevistados/as pretendem finalizar o curso e atuar como professores/as e 10,9\% responderam negativamente. Sobre a participação em atividade de pesquisa, $61,7 \%$ não participam de pesquisas, $26,8 \%$ participam e 11,5\% têm interesse em participar. Sobre a participação em atividades de Extensão, 56,8\% não participam, 23,8\% participam e 10,4\% têm interesse. No mais, 65,6 $\%$ relatam que os programas ou atividades complementares ampliam a sua formação e $34,4 \%$ relatam que não.

Considerando os dados levantados, começamos a estudar as Legislações em vigor, e começamos as discussões em torno do Projeto de Formação. Foram realizadas 21 reuniões de discussão do PPP com a comunidade acadêmica entre: plenárias, grupos de trabalho e setoriais, que consubstanciaram a presente proposta que foi elaborada, além de discussões no Núcleo Docente Estruturante e nos grupos de trabalho por áreas específicas.

Nessa perspectiva, os desafios sociais contemporâneos reverberam na Educação e nos diversos espaços educativos, exigindo proposição de novas perspectivas de formação para atuação do/a pedagogo/a. Essas perspectivas se referem não só à sua participação no exercício da docência, gestão e desenvolvimento curricular dentro do sistema regular de ensino, mas também na busca da organização coletiva, na articulação de ideias, na participação ativa dos processos mais amplos de ensino aprendizagem, pautados em seu papel político diante da função social de educar.

Desse modo, o curso de Licenciatura em Pedagogia debruçou-se sobre o fenômeno educativo em sua pluralidade, promovendo experiências teórico-práticas fundamentadas em princípios éticos, de sensibilidade ética, afetiva e estética, permeadas pela interdisciplinaridade, de forma contextualizada e baseada em vivências culturais, democráticas e na pertinência e relevância social do direito à educação.

A proposta pedagógica foi constituída por três núcleos formativos que englobam os diferentes componentes curriculares e atividades que integram a carga horária total do curso. São núcleos que compõem o currículo na perspectiva de fundamentar, aprofundar e enriquecer o percurso formativo do discente, a saber: núcleo básico, núcleo diversificado, aprofundamento e profissionalização e núcleo integrador. 
Destaca-se que a proposta do curso de Pedagogia, além de ser constituída pelos núcleos formativos, organizou-se através de duas dimensões: Pedagogia: formação, identidade e função social e Profissionalização do pedagogo: aprofundamento, diversificação e pesquisa, ambas fundamentadas em princípios éticos e valores democráticos que contribuem para a formação da identidade docente e o aprofundamento dos campos de saberes a partir de estudos teórico-práticos.

Vale ressaltar que as duas dimensões contempladas no currículo estão em movimento, pois são dinâmicas e se entrelaçam por meio de núcleos de estudos integradores que perpassam por ações, projetos e programas ligados à docência, pesquisa e extensão, disponíveis na FACED e na UFBA, de um modo geral. Sendo assim, a presente proposta coloca o discente no centro da sua formação assumindo uma posição ativa e consciente.

Após a proposta passar por todas as instâncias deliberativas da FACED/UFBA, o Projeto Pedagógico para a Licenciatura em Pedagogia foi encaminhado ao Núcleo de Currículo da Pró-Reitoria de Graduação (PROGRAD/UFBA), para análise e posterior aprovação. Enquanto aguardamos o retorno desse documento que foi gestado no bojo da Resolução 02/2015, recebemos, com espanto e estranhamento, a notícia da aprovação de uma nova Resolução n. 02/2019, dissecada dos princípios da liberdade e autonomia, a qual rejeitamos porque, entre uma de suas características, não resultou de um debate amplo nacional, mas impõe-se de forma autoritária e arbitrária.

\section{A Resolução 02/2019: esvaziamento da fundamentação epistemológica da formação}

Segundo a análise da estudiosa Helena de Freitas (2019), o Conselho Pleno e a Câmara de Educação Básica do CNE, em sessão extraordinária conjunta aprovaram, em 7 de novembro de 2019, tanto o Parecer quanto a Resolução CNE/CP 02/2019 que define as Diretrizes Curriculares Nacionais para a Formação Inicial de Professores da Educação Básica e institui a Base Nacional Comum de Formação Inicial de Professores da Educação Básica. Ainda de acordo com a autora, esses documentos constituem um retrocesso quando comparados às Diretrizes Curriculares Nacionais (DCNs) - Resolução CNE/CP 02/2015 porque, entre outras coisas, segrega a formação continuada e a pauta da valorização dos profissionais do magistério devido a mudança de concepção. 
O antagonismo da Resolução CNE/CP 02/2019: Reflexões sobre a atualização curricular do curso de Pedagogia da FACED/UFBA com base na Resolução CNE/CP 02/2015

Antes da arbitrária aprovação da referida Resolução 02/2019, ainda em outubro de 2019, tivemos na Faculdade de Educação da Universidade Federal da Bahia uma reunião que foi convocada pela ANFOPE Regional, no Auditório da FACED/UFBA, para discutir aquela proposta. Naquela ocasião, o Prof. Dr. Roberto Sidnei Alves Macedo, Professor da FACED/UFBA e especialista em Currículo, fez considerações, ponderações, críticas e teceu as seguintes problematizações acerca da Resolução CNE/CP 02/2019.

1.Total omissão quanto à obrigatória relação entre trabalho docente e formação de professores;

2.Total omissão no que se refere aos autores do campo do currículo e dos argumentos relacionando a currículo e formação de professores;

3.Total omissão no que concerne à disponibilidade de justificar de forma circunstanciada as Diretrizes em pauta para o coletivo de professores brasileiros.

4. Não há qualquer fundamentação epistemológica das proposições pautadas; 5. Omissões, lacunas conceituais e ausência de argumentos no que se refere ao modelo de currículo por competências opcionado;

6. Contradições insuperáveis quando optam ao mesmo tempo pelo modelo curricular por competências e legitimam a educação integral, argumentando em favor da interdisciplinaridade. Competências e disciplina são lógicas incompatíveis na prática curricular;

7. Compreensão simplista do fenômeno aprendizagem, optando por um cognitivismo raso e desatualizado. Sendo a aprendizagem é, ao mesmo tempo, uma pauta psicológica, social, antropológica, ética e política, portanto é sempre perspectival;

8. Opção por seguir as orientações do MEC quanto à perspectiva abstrata do "Direito ao desenvolvimento e à aprendizagem";

9. Total omissão de argumentos sobre as questões da diversidade e da diferença nos currículos e nas experiências formacionais;

10. Relação teoria e prática eivada de dicotomias e antinomias já superadas pelas epistemologias pedagógicas, simplificando de forma evidente a ideia de prática docente;

11. A política de currículo aparece como uma panaceia educacional, pecando intencionalmente ou não em distinguir bem as suas especificidades pedagógicas;

12. Não explicita de que perspectiva compreende currículo, política de currículo, formação e política de formação, bem como política de formação docente;

13. A concepção de formação é reduzida tão somente a dispositivos formacionais, omitindo qualquer argumento sobre a formação como experiência de aprendizagem sociotécnica, política, cultural, ética e espiritual, por exemplo. (MACEDO,2019).

14. Há, portanto, imensas fragilidades, lacunas, omissões e contradições no Documento, o que o desqualifica na sua totalidade como um Documento Referencial Curricular para Formação de Professores. Ademais, em face dessa falta de qualidade, permite que possamos desconstruí-lo por fora e por dentro, substituindo-o por ações formacionais qualificadas junto às escolas e seus professores. (MACEDO, 2019). 
Tais considerações foram reiteradas para sinalizar os equívocos e esvaziamento conceitual na referida Resolução 02/2019. Talvez o mais grave de todos seja a relação teoria e prática que, ao invés de se propor como unidade indissociável, há uma supervalorização ou superdimensionamento da prática em relação à teoria, reforçando uma ideia do/a professor/a tarefeiro/a que deve saber fazer. E, nesse sentido, a fundamentação teórica sobre a formação de professores/as não tem sustentação, o que Macedo (2019) denominou de esvaziamento ou omissão da "fundamentação epistemológica".

É sabido que a discussão acerca do currículo passa, em primeiro lugar, pela concepção e, em segundo lugar, encontra respaldo na concepção de educação e de formação que se deseja, coerentes com a construção de um processo formacional amparado na dimensão democrática. E é também neste sentido que Macedo (2019) critica o enfoque da atual Resolução sobre o "Direito ao desenvolvimento e à aprendizagem", ao invés de se colocar em defesa do Direito à Educação. E isso não significa que a aprendizagem não seja importante, mas é mais específica e focada, enquanto que a Educação é mais ampla e plural.

Assim, na Resolução 02/2019, em lugar da defesa da Educação e garantia da formação, há uma simplificação dos direitos à aprendizagem e especificação dos conteúdos propostos na Base Nacional Comum Curricular (BNCC, 2017) ao qual está sugerida na seara da Pedagogia das competências que, na mais grave das situações será inspecionada a partir dos exames nacionais.

Na contramão da Resolução 02/2019, a fundamentação da Proposta Curricular do Curso de Pedagogia da FACED/UFBA foi referenciada na Resolução 02/2015 por alguns motivos importantes os quais descrevemos: 1) possui uma concepção de formação inicial e continuada articulada às políticas públicas de educação; 2) demarca um compromisso na dimensão de "política institucional articulada à Educação Básica, suas políticas e diretrizes" (Art. $\left.1^{\circ} \S 3^{\circ}\right) ; 3$ ) pauta o direito fundamental à Educação para a formação da cidadania; 4) demarca a indissociabilidade entre teoria e prática; 5) trata-se de um documento democrático que passou pela discussão e aprovação da comunidade acadêmica. E, por isso, reflete muitos anseios de uma formação que desejamos para os/as egressos/as Licenciados/as em Pedagogia de nossa Universidade. Por isso mesmo, somos contrários ao engessamento que a Resolução 02/2019 traz, como um Projeto mercantilista prescritivo que tenta se impor apresentando os seguintes elementos:

i) padronizar as políticas e ações educacionais, neste caso, a formação inicial e continuada dos professores à Base Nacional Comum Curricular; ii) as demandas sociais contemporâneas, aprendizagens 
O antagonismo da Resolução CNE/CP 02/2019: Reflexões sobre a atualização curricular do curso de Pedagogia da FACED/UFBA com base na Resolução CNE/CP 02/2015

essenciais e direito de aprendizagem; iii) as competências profissionais a partir da Agenda 2030 da ONU; iv) as experiências internacionais. (CURADO SILVA, 2020, p. 102).

Como se pode perceber, a Resolução atual cerceia a autonomia docente e a liberdade de criação e criatividade da escola, quando faz a explicitação de que a padronização da formação deverá tomar como bússola a Base Nacional Comum Curricular (BNCC); do mesmo modo que resume as aprendizagens essenciais aos conteúdos propostos na BNCC; também lista dez competências gerais com as respectivas competências específicas para a docência como uma espécie de cartilha que se pretende seguir; e tudo isso, com inspiração em experiências de países que nem de longe têm uma realidade parecida com o contexto social, econômico, cultural e educacional brasileiro.

Com a Proposta de Projeto de Curso dialogada com os segmentos acadêmicos (docentes, técnicos e estudantes), em fóruns de discussão e grupos de trabalhos, aprovada nas instâncias administrativo-pedagógicas da Faculdade de Educação, o PPC de Pedagogia foi enviado ao Núcleo de Programas e Currículos da Universidade Federal da Bahia para análise e aprovação. E, nesta proposta, apresentamos a concepção que defendemos de percurso formativo na dimensão humana, ética e democrática que possibilita aos/às estudantes um aprendizado contínuo, uma articulação interdisciplinar entre diversos campos do saber considerando os desafios contemporâneos que clama por uma formação mais plural.

Com esse compromisso, buscamos organizar em núcleos formativos, considerando as especificidades que sugere que sejam "respeitadas a diversidade nacional e a autonomia pedagógica das instituições" (Art. 12, Resolução 02/2015). Inclusive podemos destacar que essa sensibilidade apresentada no documento, que orientou a atualização de nosso PPC, não é citada na Resolução 02/2019, demonstrando-se mais uma vez o autoritarismo e o desrespeito aos diversos contextos educacionais, portanto, não cabendo adaptações em consonância com as realidades locais, mas diretivas que se impõe como norma/regra que só cabe cumprir.

Ao concebermos que princípios como autonomia, justiça social, respeito à diversidade, promoção da participação democrática, abertura ao diálogo, respeito aos contrários, articulação do trabalho formativo à ética, estética e ludicidade são importantes para a formação profissional, estamos reafirmando um Projeto coletivo e solidário de formação. Esse conjunto de princípios faz parte dos núcleos propostos como possibilidade na Resolução 02/2015 (Art. 12), tais como:

I - núcleo de estudos de formação geral; 
II - núcleo de aprofundamento e diversificação de estudos das áreas de atuação profissional;

III - núcleo de estudos integradores;

A partir das diretrizes, na Proposta de Projeto Pedagógico do nosso Curso de Pedagogia, pautamos as discussões acerca das "relações entre educação e trabalho, educação e diversidade, direitos humanos, cidadania, educação ambiental, entre outras problemáticas centrais da sociedade contemporânea" (Resolução 02/2015, Art. 12, inciso I, item i), que estão diluídas nos conteúdos relacionados aos fundamentos da educação; formação na área de políticas públicas e gestão da educação, seus fundamentos e metodologias; direitos humanos; diversidades étnico racial, de gênero, sexual, religiosa, de faixa geracional; Língua Brasileira de Sinais (LIBRAS); educação especial; direitos educacionais de adolescentes e jovens em cumprimento de medidas socioeducativas. E de forma mais específica, discutimos e encaminhamos, para aprovação nas instâncias superiores da Universidade, uma Proposta de formação embasada em duas grandes dimensões, quais sejam: "Dimensão Pedagogia: formação, identidade e função social e; Dimensão Profissionalização do/a pedagogo/a: aprofundamento, diversificação e pesquisa".

DIMENSÃO PEDAGOGIA: FORMAÇÃO, IDENTIDADE E FUNÇÃO SOCIAL - essa dimensão busca fundamentar conceitos básicos da docência, da valorização do magistério, da função social da escola e da atuação do educador em espaços escolares e não escolares. O percurso formativo da/o estudante tem como objetivo conhecer, discutir e refletir os fundamentos teóricos, concepções de educação, princípios legais e valores sociais da formação e identidade do/a pedagogo/a.

DIMENSÃO PROFISSIONALIZAÇÃO DO/A PEDAGOGO/A: APROFUNDAMENTO, DIVERSIFICAÇÃO E PESQUISA - essa dimensão volta-se para a relação entre os campos de saberes e de atuação com a finalidade de que o/a estudante reflita e assuma, em diversos processos educativos, a responsabilidade de sua formação com autonomia. Tem como objetivo aprofundar a relação do/a estudante com a docência, a gestão e a pesquisa, além de refletir sobre as suas práticas educativas. (FACED-UFBA, PROJETO PEDAGÓGICO DO CURSO DE LICENCIATURA EM PEDAGOGIA, 2019, s/p).

Com as duas dimensões fica claro que projeto formativo defendemos, com os propósitos, as finalidades e os princípios da formação plena, não segregada, como propõe a Resolução 02/2019 em que almeja um licenciado dócil, obediente, produtivista e alienado. E nós negamos esse perfil para os/as egressos/as do Curso de Pedagogia da FACED/UFBA quando tomamos posição e defendemos uma formação de qualidade 
O antagonismo da Resolução CNE/CP 02/2019: Reflexões sobre a atualização curricular do curso de Pedagogia da FACED/UFBA com base na Resolução CNE/CP 02/2015

comprometida em contribuir para o processo formacional de futuros/as professores/as, enquanto profissionais críticos/as, criativos/as, intelectuais, pesquisadores/as que tomam decisões sem ser cooptados/as, que se movimentam de forma solidária e colaborativa exercendo a cidadania plena e contribuindo para a formação dos sujeitos da Educação Básica. Portanto, se distanciando daquela "panaceia educacional" como bem explicitou Macedo (2019) ao se referir às lacunas presentes no novo documento (Resolução 02/2019).

Segundo Aguiar e Dourado (2019, p. 35) neste novo documento prevalece "a padronização curricular, a submissão, aos padrões da OCDE, a orientação de segmentos do setor privado". Ou seja, há um projeto em curso de privatização e mercantilização da Educação em Curso que pretende abrir caminho para empresas com muito dinheiro, fazerem seus investimentos rentáveis na área Educacional, como uma espécie de fábrica que produz em larga escala para atender ao mercado: abrindo cada vez mais instituições de ensino (sem investir na pesquisa e extensão), contratando profissionais para ensinar que possuam conhecimentos básicos sobre uma área (notório saber), com condições de trabalho precarizadas, baixos salários e sem uma carreira. É o desenho de um maquiavélico Projeto que visa à destruição da carreira docente que já está tão fragilizada.

Neste contexto, as implicações da Resolução CNE/CP n ${ }^{\circ}$ 02/2019 para o curso de Pedagogia são desastrosas e graves porque são gestadas no bojo das políticas neoliberais, privatistas, com discursos de contenção de gastos, articulando-se aos princípios da eficiência e eficácia que resultam na formação de um profissional competente, que por seu esforço e mérito é capaz de superar os obstáculos da vida. Essas se constituem em características próprias do empresariado que não vê a Educação pública como investimento, mas como gasto e, de forma contraditória, investe como negócio que pode aumentar o capital.

Essa "(de)formação", nas palavras de Curado Silva (2020), não atende às necessidades das pessoas jovens e adultos/as que estudam no Curso de Pedagogia de nossa instituição porque são estudantes que, em sua maioria, tem baixa renda, estudaram em escolas públicas e, em muitos casos, são os/as primeiros/as a conseguir uma formação em Nível Superior em suas famílias. São estudantes que percebem na Universidade a possibilidade de uma formação digna, potente, que oportuniza uma formação plural, que abre portas não apenas para o ensino no ambiente escolar, mas para a atuação em outros espaços não escolares. 
Sob a análise de Curado Silva (2020), a Resolução 02/2019 é perigosa, especialmente nos seguintes eixos: concepção de professor; formação inicial e continuada; trabalho docente e gestão. E corroboramos com a autora quando especifica que nos primeiros dois artigos desse documento fica explícita a concepção de professor/a que é "refém" das competências e "escravo" dos conteúdos da BNCC quando sugere, de forma equivocada, que lá estarão guardadas as aprendizagens essenciais que devem ser asseguradas aos/às educandos/as da Educação Básica. No que se refere ao eixo da formação inicial e continuada, defendemos que seja realizada na Universidade Pública, com experiências formativas que envolvam o tripé da Universidade (ensino, pesquisa e extensão) e que sistematizamos as possibilidades no Projeto do Curso de Pedagogia enviado à Prograd/UFBA.

Acreditar na Universidade e defendê-la é um compromisso político necessário de reafirmação do lugar de produção de conhecimento de qualidade, por isso, é o lugar ideal para essa dinâmica formativa que, segundo Curado Silva (2020, p. 114) "realiza-se na medida em que a universidade pública contribui para a função social da escola, ou seja, para a instrumentalização de um ensino no qual se possa garantir a educação de qualidade socialmente referenciada e a universalização da educação". Também é nosso compromisso ético-político lutarmos por essa universalização, uma vez que é uma garantia constitucional que ainda não é assegurada.

Ainda seguindo a análise de Curado Silva (2010, p. 116), outro eixo é o trabalho docente e a gestão que, na Resolução 02/2015 congregava a "unidade entre formação inicial, continuada, valorização e condições de trabalho", mas que é resumida no novo documento, tomando por base "as competências docentes compostas por três dimensões: o conhecimento, a prática e o engajamento profissional" (ibid). O saber fazer é uma realidade imposta nesta Resolução 02/2019 que está empenhada em formar um professor que ensine e que seu fim último seja ensinar. O que determina a BNCC, portanto, reforça a ideia de formação pelas competências e deixa a responsabilidade sobre o sujeito que precisa empreender todo seu esforço para concluir sua formação.

Ao priorizar o debate acerca das competências, a BNNC/CFP secundariza a questão do trabalho docente e não aborda as dimensões fundamentais do seu desenvolvimento e valorização, tais como: concurso público (estabilidade) e dedicação exclusiva (em uma única escola); salários dignos e planos de cargo e carreira; infraestrutura; salas com menos alunos; apoio pedagógico da coordenação escola; existência de materiais de apoio pedagógico e tecnológico, entre outros. (CURADO SILVA, 2020, p. 117). 
O antagonismo da Resolução CNE/CP 02/2019: Reflexões sobre a atualização curricular do curso de Pedagogia da FACED/UFBA com base na Resolução CNE/CP 02/2015

Mais uma vez fica claro o projeto formativo para os/as futuros/as profissionais do magistério, que serão controlados/as, fiscalizados/as por meio de avaliações em caráter de exames externos que reduzem ou retiram a autonomia e a criticidade desse/a profissional. Resulta desse processo a precarização e o excesso de trabalho, os baixos salários, a desvalorização que pode sucumbir definitivamente a carreira do magistério que já tem sofrido duros ataques e não tem sido atraente para a formação de novas profissões.

\section{Considerações}

Diante desse contexto de implicações de retrocessos da Resolução 02/2019, Aguiar e Dourado (2019, p. 37) asseguram que isso tudo "requer discussões e lutas em prol da defesa dos marcos constitucionais, visando garantir o Estado Democrático de Direito e a defesa histórica da educação básica, pública, laica, gratuita, democrática e de qualidade social para todos e todas". Ou seja, não devemos abrir mão das conquistas e não devemos retroceder porque temos um Projeto de Educação inclusivo, propositivo de ações pautadas na indissociabilidade entre teoria e prática.

Defendemos a Resolução 02/2015 que orientou a atualização de nosso Projeto Pedagógico do Curso de Pedagogia da FACED/UFBA, amparado em uma formação inicial de qualidade, implicado e articulado pela diversidade, "considerando as diferenças de ritmos e formas de aprendizagem decorrentes ou não de deficiência, natureza ambiental-ecológica, étnico-raciais, de gêneros e sexualidades, faixas geracionais, classes sociais, religiões, necessidades educacionais especiais, entre outras". (FACED-UFBA, PROJETO PEDAGÓGICO DO CURSO DE LICENCIATURA EM PEDAGOGIA, 2019, s/p). Esse conjunto de conhecimentos não é abordado na nova Resolução porque não interessa aquilo que é diverso, mas tão somente a manutenção de uma hierarquia, de uma ordem, de um alinhamento ao conservadorismo e tradicionalismo.

Como já sinalizado, a justificativa para utilizarmos como referencial a Resolução 02/2015 para a atualização da Proposta Curricular do Curso de Pedagogia de nossa Universidade foi que encontramos respaldo e fundamentação do que compreendemos e defendemos como ato de currículo e formação de professores/as. Nesse sentido, foi que organizamos uma trajetória formativa em torno de duas grandes dimensões, já citadas anteriormente: Dimensão Pedagogia: Formação, Identidade e Função Social que tem como objetivo conhecer, discutir e refletir os fundamentos teóricos, concepções de educação, princípios legais e valores sociais da formação e identidade do pedagogo. Ou seja, construímos uma possibilidade de currículo com fundamentação teórica acerca da 
formação docente e; Dimensão Profissionalização do Pedagogo: Aprofundamento, Diversificação e Pesquisa que tem como objetivo aprofundar a relação do estudante com a docência, a gestão e a pesquisa, além de refletir sobre as suas práticas educativas.

Cabe dizer que além da experiência com ensino, pesquisa e extensão na Universidade há um conjunto de relações afetivas que não podem ser substituídas, por isso, fazemos coro em defesa de uma formação inicial presencial, com possibilidade de trocas de saberes e ampliação de conhecimentos a partir da construção sensível, do olho no olho, que capta as necessidades formativas e reorienta os caminhos da produção de saberes.

Em linhas gerais, defendemos uma formação que não seja: de "faz de conta", de trabalhadores alienados e cumpridores de tarefas, refém do capital, dócil e obediente, conformada e submissa, como propõe a Resolução 02/2019. Ao contrário, estamos irmanados/as na luta por uma formação que seja: de formadores/as de opinião, comprometidos/as ético e socialmente com a formação humana, cidadã e crítica, profissionais solidários e colaborativos, insubordinado e autônomo, reflexivo e propositivo, sensível com a diversidade dos contextos educativos, implicados com a possibilidade de uma Educação universalizada.

\section{Referências}

AGUIAR, Márcia Angela da Silva; DOURADO, Luiz Fernandes. BNCC e formação de professores: concepções, tensões, atores e estratégias. Revista Retratos da Escola, Brasília, v. 13, n. 25, p. 33-37, jan./mai. 2019. Disponível em: $<$ http//www.esforce.org.br>. Acesso em: 28/Out./2020.

AGUIAR, Márcia Angela da S. (et al). Diretrizes curriculares do curso de pedagogia no Brasil: disputas de projetos no campo da formação do profissional da educação. Educação \& Sociedade, Campinas, SP, v. 27, n. 96, especial, p. 819-842, 2006. Disponível em: https://www.scielo.br/j/es/a/sckL7kBHbJtY3VnqMNTFVQf/?format=pdf\&lang=pt.

Acesso em: 12/Set./2020.

ANFOPE. XVIII Encontro Nacional sob a coordenação da Associação Nacional Pela Formação dos Profissionais da Educação. Tema: Políticas de Formação de Professores: conjuntura nacional, avanços e retrocessos. Pontifícia Universidade Católica de Goiás,

Goiânia, 2016. Disponível em: <https://www.anfope.org.br/wpcontent/uploads/2018/05/Doc-FINAL-XVIII-ENANFOPE-6_3_2017-

Coordena\%C3\%A7\%C3\%A3o-Iria.pdf>. Acesso em: 11/Set./2020.

BRASIL. Base Nacional Comum Curricular (BNCC). Educação é a Base. Brasília, MEC/CONSED/UNDIME, 2017. 
O antagonismo da Resolução CNE/CP 02/2019: Reflexões sobre a atualização curricular do curso de Pedagogia da FACED/UFBA com base na Resolução CNE/CP 02/2015

BRASIL. Lei n. 5.692, de 11 de agosto de 1971. Fixa Lei de Diretrizes e Bases da Educação Nacional. Diário Oficial da União, Brasília, DF, 1971.

Parecer n. 03, de 21de fevereiro de 2006. Reexame do Parecer CNE/CP n ${ }^{\circ}$ 5/2005, que trata das Diretrizes Curriculares Nacionais para o Curso de Pedagogia. Disponível em: <http://portal.mec.gov.br/cne/arquivos/pdf/pcp003_06.pdf >. Acesso em: 2/Set./2020.

Parecer $n .05$, de 13 de dezembro de 2005. Define as Diretrizes Curriculares Nacionais para o Curso de Pedagogia. Disponível em: $<$ http://portal.mec.gov.br/cne/arquivos/pdf/pcp05_05.pdf >. Acesso em: 2/Set./ 2020.

Resolução CNE/CP n. 02, de 01de julho de 2015. Define as Diretrizes Curriculares Nacionais para a formação inicial em nível superior [cursos de licenciatura, cursos de formação pedagógica para graduados e cursos de segunda licenciatura] e para a formação continuada. Disponível em: <http://portal.mec.gov.br/docman/agosto-2017pdf/70431-res-cne-cp-002-03072015-pdf/file>. Acesso em: 2/Set./2020.

Resolução CNE/CP n. 02, de 20 de dezembro de 2019. Define as Diretrizes Curriculares Nacionais para a Formação Inicial de Professores para a Educação Básica e institui a Base Nacional Comum para a Formação Inicial de Professores da Educação Básica [BNC-Formação]. Disponível em: <http://portal.mec.gov.br/docman/dezembro2019-pdf/135951-rcp002-19/file>. Acesso em: 2/Set./2020.

CURADO SILVA, Kátia Augusta Pinheiro Cordeiro da. A (de) Formação de Professores na Base Nacional Comum Curricular. In: UCHOA, Antonio Marcos da Conceição; LIMA, Átila de Menezes; SENA, Ivânia Paula Freitas de Souza (Orgs.). Diálogos críticos, volume 2: reformas educacionais: avanço ou precarização da educação pública? Porto Alegre, RS: Editora Fi, 2020. p. 102-122.

FACED-UFBA. Projetos Pedagógicos dos Cursos de Licenciatura em Pedagogia da Faculdade de Educação da UFBA. Salvador, 2012. Disponível em: $<$ https://faced.ufba.br/sites/faced.ufba.br/files/curriculo_do_curso_de_licenciatura_em pedagogia.pdf.>. Acesso em: 07/Ago./2020.

FACED-UFBA. Projeto Pedagógico do Curso de Licenciatura em Pedagogia. Salvador, 2019. [Documento em estágio de análise na PROGAD-UFBA].

GIL, Antonio Carlos. Como elaborar projetos de pesquisa. 4. ed. São Paulo: Atlas, 2008.

LIBÂNEO, José Carlos; PIMENTA, Selma Garrido. Formação de profissionais da educação: visão crítica e perspectiva de mudança. Educação \& Sociedade, São Paulo, ano XX, n. 68, p. 239-277, dez. 1999. Disponível em: https://www.scielo.br/pdf/es/v20n68/a13v2068.pdf. Acesso em: 18/Ago./2020.

MACEDO, Roberto Sidnei. Escolas como espaçostempos de políticas singulares de currículo e formação. Revista Diálogo Educacional, v. 18, n.59, p. 1312-1327, 
out/dez.2018. Disponível em: <file:///C:///Users/rejan/Downloads/23533-45730-1PB.pdf>. Aceso em: 11/Ago./2020.

Reunião da Anfope Regional da Bahia sobre a Resolução 02/2019. Salvador: Faculdade de Educação da Universidade Federal da Bahia, Out., 2019.

SAVIANI, Dermeval. História das ideias pedagógicas no Brasil. 3. ed. rev. Campinas, SP: Autores Associados, 2010.

Recebido em: 27 jan. 2021. Aprovado em: 12 jul. 2021.

* Ronaldo Figueiredo Venas é Professor da Faculdade de Educação da Universidade Federal da Bahia - UFBA. Doutor e Mestre em Educação pela UFBA. Graduação em História e Pedagogia. Pesquisador na linha de História da Educação e Formação de Professores. Excoordenador do curso de Pedagogia da UFBA.

E-mail: rvenas@ufba.br

ORCID: https://orcid.org/0000-0002-6319-7985

** Rejane de Oliveira Alves é Professora da Faculdade de Educação da Universidade Federal da Bahia - UFBA. Doutora em Educação pela UnB, Mestre em Educação pela UFPI e Pedagoga. Coordenadora do Grupo de Estudos e Pesquisas em Avaliação para Aprendizagem - FACED/UFBA. Ex-coordenadora do curso de Pedagogia da UFBA.

E-mail: rejane.alves@ufba.br

ORCID: http://orcid.org/0000-0002-4632-0013

*** Leila da Franca Soares é Professora da Faculdade de Educação da Universidade Federal da Bahia - UFBA. Doutora e Mestre em Educação pela UFBA e Pedagoga. Membro do Núcleo Integrado de Estudos e Pesquisas sobre Infâncias e Educação InfantilNEPESSI/FACED/UFBA e pesquisadora do Grupo de Estudos e Pesquisas em Educação Infantil, Crianças, Infâncias-GEPEICI/FACED/UFBA. Ex-vice-coordenadora do curso de Pedagogia da UFBA.

E-mail: leilafs@ufba.br

ORCID: https://orcid.org/0000-0003-1426-3429 